Supplement of Clim. Past, 14, 1-20, 2018

https://doi.org/10.5194/cp-14-1-2018-supplement

C Author(s) 2018. This work is distributed under

the Creative Commons Attribution 3.0 License.

(c) (1)

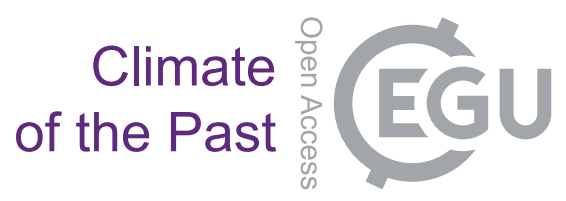

Supplement of

\title{
Effects of undetected data quality issues on climatological analyses
}

\section{Stefan Hunziker et al.}

Correspondence to: Stefan Hunziker (stefan.hunziker@giub.unibe.ch)

The copyright of individual parts of the supplement might differ from the CC BY 3.0 License. 


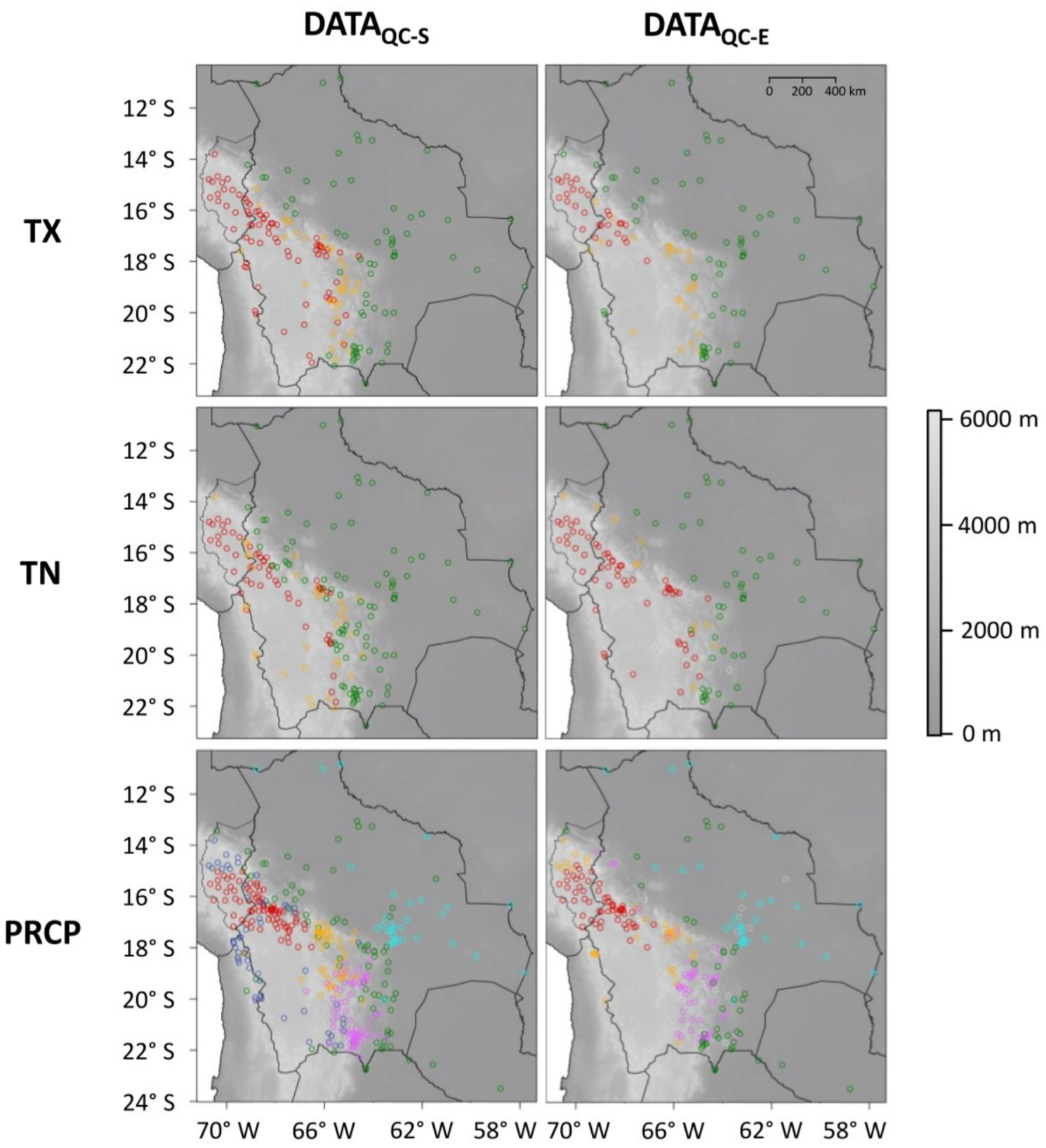

Figure S1: Station clusters in the Central Andean area arising from the agglomerative hierarchical clustering with complete linkage of the correlation matrices. Clusters for maximum temperature (TX, first row), minimum temperature (TN, second row), and precipitation (PRCP, third row) are shown. Maps in the first column illustrate the clusters for the dataset quality controlled with a 5 standard method (DATA $\mathrm{QC}_{\mathrm{Q}-\mathrm{S}}$ ), and maps in the second column show the clusters for the dataset quality controlled with an enhanced method (DATAQC-E). Each colour indicates one cluster, and white circles mark station time series that did not share $\geq 120$ common valid months with $\geq \mathbf{1 0}$ neighbouring station records. Clusters covering similar areas were identically coloured. Even though there are differences in the clusters derived from DATAQC-S and DATAQC-E, the overall cluster structures are similar. For example, the three main regions Altiplano, Valleys, and Lowlands are captured for TX and TN. The grey background shading indicates the elevation in $\mathbf{m}$ a.s.l. 